\title{
ESTATUTO DA PESSOA COM DEFICIÊNCIA, DIREITOS FUNDAMENTAIS E OS CONFLITOS DIANTE DA REALIDADE EMPÍRICA: BREVES APONTAMENTOS SOB A ÓTICA DO DIREITO E DA PSIQUIATRIA
}

\section{Patrício Jorge Lobo Vieira *}

Resumo: O Estatuto da Pessoa com Deficiência alterou o sistema da capacidade civil e consagrou uma dinâmica inclusiva. A mente humana possui especificidades e pessoas podem não dispor da autonomia necessária à realização de atos na vida civil, conforme aspectos delineados pela Psiquiatria. Há discordâncias quanto aos limites da curatela, no tocante ao aspecto patrimonial e extrapatrimonial. A finalidade do artigo, em estudo de natureza exploratória e descritiva, com abordagem qualitativa e método dedutivo, é trazer reflexões acerca da problemática, buscando soluções para s casos em que a ausência de autonomia gera risco à própria pessoa.

Palavras-chave: Pessoa com deficiência. Direitos Fundamentais. Realidade empírica. Conflitos. Curatela.

\section{DISABLED PERSON STATUTE, FUNDAMENTAL RIGHTS AND CONFLICTS BEFORE EMPIRICAL REALITY: BRIEF NOTES UNDER THE OPTICS OF LAW AND PSYCHIATRY}

\begin{abstract}
The Disabled Person Statute has changed the civilian capacity system and has created an inclusive dynamics. The human mind has specificities and it is possible some people do not have the necessary autonomy to perform certain acts of civil life, according to Psychiatry. There are disagreements about the limits of guardianship, regarding the patrimonial and nonpatrimonial aspects. That way, through exploratory and descriptive study, with qualitative approach and deductive method, this work aims to reflect on the problem, by looking for solutions that optimize rights when the absence of autonomy brings risks to the person.
\end{abstract}

Keywords: Person with Disability. Fundamental Rights. Empirical Reality. Conflicts. Guardianship.

\section{INTRODUÇÃO}

\footnotetext{
* Bacharel em Direito pela UFPB. Especialista em Direito Eleitoral. Especialista em Direito Civil e Processual Civil. Mestrando em Direito Constitucional pela UFRN. Juiz de Direito do TJ-RN. Professor Universitário. Endereço postal: Rua Doutor Moises da Costa Lopes, n. 621, Nova Betânia, Mossoró-RN. E-mail: patricio_lobo@hotmail.com.
}

Revista Brasileira de Direito Civil em Perspectiva | e-ISSN: 2526-0243| Porto Alegre | v. 4 | n. 2 |

p. $20-38$ | Jul/Dez. 2018 


\section{ESTATUTO DA PESSOA COM DEFICIÊNCIA, DIREITOS FUNDAMENTAIS E OS CONFLITOS DIANTE DA REALIDADE EMPÍRICA: BREVES APONTAMENTOS SOB A ÓTICA DO DIREITO E DA PSIQUIATRIA}

Após a edição da Lei Federal n. ${ }^{\circ}$ 13.146/2015 emergiu no ordenamento jurídico brasileiro o denominado Estatuto da Pessoa com Deficiência, a Lei Brasileira da Inclusão, um denso arcabouço legal envolvendo temáticas civis, penais e processuais no respeitante a pessoa com deficiência.

Segundo estimativas da OMS, uma em cada quatro famílias tem ou terá pelo menos um membro que sofre transtorno mental ou comportamental, e o impacto sobre os indivíduos, as famílias, as comunidades e a sociedade em geral é extremamente considerável. Poucas obras jurídicas envolvem o estudo do tema, exigindo-se maturação não apenas nas ciências jurídicas, mas médicas e afins.

O objetivo do presente artigo é abordar as nuances dos direitos fundamentais da pessoa com deficiência no contexto da realidade social. Inicialmente, será realizada exposição no tocante ao Estatuto da Pessoa com Deficiência, delineando-se os contornos alusivos à dignidade humana e autonomia do ser humano, orientando-se o estudo no respeitante às significativas alterações implementadas pela legislação especial. Na sequência, será realizada uma reflexão no respeitante aos problemas porventura existentes e a surgir no tocante à efetivação dos direitos da pessoa com deficiência no contexto da realidade empírica, sobretudo em relação à índole garantista da pessoa com vulnerabilidade, no sentido de se aferir se, na prática, os direitos fundamentais consagrados no Estatuto realmente estariam a homenagear a dignidade das pessoas com deficiência, ou se as situações da vida real poderiam criar um empecilho aos seus direitos, estimulando-se a discussão acerca da possibilidade ou não de extensão dos limites da curatela em relação a questões extrapatrimoniais.

O referencial teórico envolve a Constituição Federal, a Lei Brasileira da Inclusão, o Código de Processo Civil, doutrina e literatura médica, através de estudo de natureza exploratória e descritiva, com abordagem qualitativa. Será utilizado o método dedutivo como forma de abordagem e, na dimensão metodológica procedimental, adotar-se-á a pesquisa bibliográfica para avaliar o estado da arte quanto ao objeto do estudo proposto. Neste tocante, realizar-se-á estudo pautado em aferição teórica, com análise da doutrina especializada, de modo a buscar as contribuições teóricas existentes sobre o assunto. No respeitante ao conhecimento das condicionantes do problema, no âmbito da organização, aplicar-se-á o método de análise

Revista Brasileira de Direito Civil em Perspectiva | e-ISSN: 2526-0243| Porto Alegre | v. 4 | n. 2 |

p. 20 - 38 | Jul/Dez. 2018 
documental, visando examinar documentos que colaborem para a melhor compreensão das circunstâncias sociais, legais, econômicas e terapêuticas sobre o objeto do estudo proposto.

Face ao panorama acima descrito, emerge o seguinte problema de pesquisa: em que medida os direitos fundamentais consagrados no Estatuto da Pessoa com Deficiência poderão ser efetivados, quando a realidade empírica não permitir a concretização dos direitos? É possível a extensão dos efeitos da curatela a questões extrapatrimoniais?

Derivam desse problema algumas questões norteadoras que merecem investigação. A consagração de direitos existenciais e a limitação da curatela ao âmbito patrimonial preserva ou prejudica os direitos fundamentais da pessoa com deficiência? Nos casos em que o grau de discernimento for mentalmente comprometido, poderia o curador postular medida judicial protetiva em favor do curatelado, mesmo com a limitação legal ao aspecto negocial e patrimonial?

Avulta desses questionamentos uma hipótese básica, a qual merece ser testada, que é a seguinte: o reconhecimento da capacidade civil relativa às pessoas com deficiência, como medida de reconhecimento dos direitos fundamentais e da dignidade humana não impede a extensão da curatela a atos de natureza não patrimonial (existenciais), dependendo do grau da deficiência, quando comprometida a própria consciência acerca do seu conteúdo.

\section{O ESTATUTO DA PESSOA COM DEFICIÊNCIA. O NOVO SISTEMA JURÍDICO, A DIGNIDADE HUMANA E A AUTONOMIA}

A temática envolvendo incapacidade civil permaneceu, por vários anos, vinculada à ideia de ser humano diminuto, sem aptidão para os seus próprios direitos existenciais.

Com a publicação da Lei Federal n. ${ }^{\circ}$ 13.146/2015, instituidora do Estatuto da Pessoa com Deficiência, a denominada Lei Brasileira da Inclusão, concretizou-se um dos mais significativos momentos na história do constitucionalismo brasileiro,

De fato, com o advento da referida Lei, consolidou-se, no plano legislativo e de maneira compilada, a política de inclusão da pessoa com deficiência, com o fito de assegurar e promover,

Revista Brasileira de Direito Civil em Perspectiva | e-ISSN: 2526-0243| Porto Alegre | v. 4 | n. 2 |

p. 20 - 38 | Jul/Dez. 2018 


\section{ESTATUTO DA PESSOA COM DEFICIÊNCIA, DIREITOS FUNDAMENTAIS E OS CONFLITOS DIANTE DA REALIDADE EMPÍRICA: BREVES APONTAMENTOS SOB A ÓTICA DO DIREITO E DA PSIQUIATRIA}

em condições de igualdade, o exercício dos direitos e das liberdades fundamentais da pessoa com deficiência, visando à sua inclusão social e cidadania.

Segundo a mencionada previsão normativa, considera-se pessoa com deficiência aquela que tem impedimento de longo prazo de natureza física, mental, intelectual ou sensorial, o qual, em interação com uma ou mais barreiras, pode obstruir sua participação plena e efetiva na sociedade em igualdade de condições com as demais pessoas.

Consoante estatui o art. $6^{\circ}$ do Estatuto da Pessoa com Deficiência, a existência da deficiência não afeta a plena capacidade civil da pessoa, consagrando, desse modo, uma gama de direitos aos portadores de necessidades especiais, categorizando como dever do Estado, da sociedade e da família assegurar à pessoa com deficiência, com prioridade, a efetivação dos direitos referentes à vida, à saúde, à sexualidade, à paternidade e à maternidade, à alimentação, à habitação, à educação, à profissionalização, ao trabalho, à previdência social, à habilitação e à reabilitação, ao transporte, à acessibilidade, à cultura, ao desporto, ao turismo, ao lazer, à informação, à comunicação, aos avanços científicos e tecnológicos, à dignidade, ao respeito, à liberdade, à convivência familiar e comunitária, entre outros decorrentes da Constituição Federal, da Convenção sobre os Direitos das Pessoas com Deficiência e seu Protocolo Facultativo e das leis e de outras normas que garantam seu bem-estar pessoal, social e econômico.

Decerto, a incapacidade civil absoluta, doravante, apenas vincula-se aos menores de 16 (dezesseis) anos de idade, sendo revogados os incisos do art. 3. ${ }^{\circ}$ do Código Civil, relacionados aos que por enfermidade ou deficiência mental, não tiverem o necessário discernimento para a prática desses atos, e os que, mesmo por causa transitória, não puderem exprimir sua vontade. No aspecto relativo à incapacidade relativa, foram alterados dispositivos, de maneira que se inserem, nessa conceituação, os maiores de dezesseis anos e menores de dezoito, os ébrios habituais e os viciados em tóxico, bem como aqueles que, por causa transitória ou permanente, não puderem exprimir sua vontade. $\mathrm{Na}$ esteira da nova sistemática legal, o Estatuto também alterou as disposições relacionadas à curatela, modificando a redação dos artigos 1.767 e seguintes do CC, de maneira que apenas estão sujeitos à curatela aqueles que, por causa transitória ou permanente, não puderem exprimir sua vontade, os ébrios habituais e os viciados em tóxico, revogando os incisos II e IV do art. 1.767.

Revista Brasileira de Direito Civil em Perspectiva | e-ISSN: 2526-0243| Porto Alegre | v. 4 | n. 2 |

p. 20 - 38 | Jul/Dez. 2018 
Sobreleva destacar, ainda, a necessidade de entrevista pessoal do juiz com a pessoa curatelada, bem como da manifestação de equipe multidisciplinar, deliberando-se, ao final, os limites da curatela, segundo as potencialidades da pessoa, volvido às restrições constantes do art. 1.782, após o que indicará pessoa para o exercício da curatela, levando em conta a vontade e as preferências da parte, a ausência de conflito de interesses e de influência indevida, a proporcionalidade e a adequação às circunstâncias da pessoa, nada impedindo o estabelecimento da curatela compartilhada ou fragmentada.

Forçoso, outrossim, registrar a inserção, na ordem jurídica, do instituto da Tomada de Decisão Apoiada, processo pelo qual, conforme art. 1.783-A do Código Civil, a pessoa com deficiência elege pelo menos duas pessoas idôneas, com as quais mantenha vínculos e que gozem de sua confiança, para prestar-lhe apoio na tomada de decisão sobre atos da vida civil, fornecendo-lhes os elementos e informações necessários para que possa exercer sua capacidade.

Optou o legislador, pois, na percepção de Flávio Tartuce (2018, p. 86), pela substituição da dignidade-vulnerabilidade pela dignidade-liberdade, de maneira que a pessoa com deficiência "tem assegurado o direito ao exercício de sua capacidade legal em igualdade de condições com as demais pessoas. Eventualmente, quando necessário, a pessoa com deficiência será submetida à curatela conforme a lei".

A legislação inovadora, desse modo, busca concretizar o disposto no art. $1^{\circ}$ da Constituição Federal, consubstanciando a dignidade humana e orientando toda a ordem jurídica nacional em relação à pessoa com deficiência, realçando a complexidade do ser humano, a sua autonomia e racionalidade em uma base descritiva mais ampla, vinculada à inteligência, sentimento e reflexidade na forma cognitiva, volitiva e normativa (ALEXY, 2015, p. 23 a 25), valorizando-se o indivíduo na sua dimensão subjetiva e pessoal, para a valorização do indivíduo sobre o grupo ou a comunidade real ou artificial em que se integra, para a garantia jurídica da possibilidade de cada um poder prosperar, em liberdade e autonomia, como pessoa humana (NOVAES, 2017, p. 59).

A Lei da Inclusão incorporou preceitos consagrados na ordem internacional, expressando a essência da Declaração Universal dos Direitos Humanos, em seus artigos $1^{\circ}$ e $2^{\circ}$, no sentido de igualdade, liberdade, respeito e dignidade entre os seres humanos, como também da 


\section{ESTATUTO DA PESSOA COM DEFICIÊNCIA, DIREITOS FUNDAMENTAIS E OS CONFLITOS DIANTE DA REALIDADE EMPÍRICA: BREVES APONTAMENTOS SOB A ÓTICA DO DIREITO E DA PSIQUIATRIA}

Convenção sobre os Direitos das Pessoas com Deficiência (CDPD), quando adotou uma ampla categorização de pessoas com deficiência, reafirmando que todas as pessoas com todos os tipos de deficiência devem gozar de todos os direitos humanos e liberdades fundamentais.

Na realidade, o grande impacto o respeitante à capacidade civil e à dignidade da pessoa humana, volvida ao aspecto da pessoa com algum impedimento, vincula-se à denominada autonomia, seja na seara pública, seja no âmbito privado. Referida autonomia estaria vinculada à faculdade de todo gênero humano de se autodeterminar, de fazer suas opções e escolhas no dia a dia, como também de participar dialógica e ativamente das escolhas e deliberações políticas da comunidade na qual se encontra inserido. Qualidade intrínseca ao ser humano que, na concepção de Daniel Sarmento (2016, p. 140) corresponde à faculdade do indivíduo de fazer e implementar escolhas concernentes à sua própria vida, expressando a autodeterminação individual, resultando no reconhecimento do ser humano como um agente moral, capaz de decidir o que é bom ou ruim para si, e com o direito de seguir a sua decisão, desde que ela não viole direitos alheios. É o que, segundo o autor, Ronald Dworkin denomina de 'independência ética', qual seja, a prerrogativa do indivíduo, que envolve a possibilidade de realizar escolhas fundamentais e de, em alguma medida, estar ao leme da sua própria existência, configurando-se o que Ricardo Lobo Torres (2001, p. 265) denomina de núcleo essencial da cidadania.

Nesse ponto, Barroso (2016, p. 82), elenca três condicionantes, a saber: a razão (a capacidade mental de tomar decisões informadas), a independência (a ausência de coerção, de manipulação e de privações essenciais) e a escolha (a existência real de alternativas), ou seja, para a autonomia seria a capacidade de toda pessoa humana de tomar decisões e de fazer escolhas pessoais na sua vida, baseadas na sua própria concepção de bem, sem influências externas indevidas. Referida autonomia poderia, em tese, ser restringida, na opinião do autor (BARROSO, 2016, p. 88), para proteção dos direitos e da dignidade do próprio indivíduo, de terceiros e de valores sociais compartilhados, até mesmo, na opinião de Stuart Mil, apud Barroso (2016, p. 89), para impedir comportamentos nocivos, seja em nome da noção de princípio do dano, ou do conceito de princípio da ofensa, defendido por Joel Feinberg.

A busca de soluções em relação ao assunto perpassa pela interdisciplinaridade e adoção de políticas públicas inclusivas, solidárias e protetivas, que permitam a promoção dos direitos

Revista Brasileira de Direito Civil em Perspectiva | e-ISSN: 2526-0243| Porto Alegre | v. 4 | n. 2 |

p. 20 - 38 | Jul/Dez. 2018 
essenciais das pessoas com deficiência, máxime na seara da saúde mental, dada a sua própria complexidade.

\section{APONTAMENTO INTERDISCIPLINAR. A CAPACIDADE CIVIL, O DIREITO E A PSIQUIATRIA: UM DIÁLOGO NECESSÁRIO}

$\mathrm{O}$ momento atual exige mudança de paradigmas, de maneira que a acessibilidade e o rompimento de barreiras não se limitem ao aspecto físico, mas sobretudo no respeitante à efetiva inclusão das pessoas com deficiência, permitindo-se e estimulando-se o desenvolvimento da sua autonomia, participação política, cultural, social e familiar, porquanto sujeitos de direito na ordem jurídica nacional e internacional.

Imprescindível a confluência com outros ramos e ciências, notadamente da saúde, e, especificamente, a Psiquiatria. No âmbito do Direito, a análise comportamental e mental se apresentam como expressões inerentes ao estudo jurídico, notadamente no âmbito cível, relativamente à capacidade civil, ao discernimento para a prática de atos, compreensão, percepção da realidade, e, na seara penal, no respeitante à capacidade de autodeterminação relativamente à prática de crimes, por exemplo. Na curatela, por sua vez, o universo psiquiátrico e o jurídico se irmanam em uma verdadeira simbiose cujo estudo afigura-se indispensável a fim de que se extraiam análises e conclusões relacionadas ao ser humano em sua integralidade.

Daniel Martins de Barros e Antonio de Pádua Serafim (2009, p. 175-177) aduzem que:

a interface entre a Psiquiatria e o Direito, embora seja necessária, é complexa e difícil, já que enquanto a linguagem médica descreve o estado do paciente em uma escala que vai de grave a completamente saudável, a linguagem jurídica é binária: o doente é capaz ou incapaz, necessita ser internado, ou não, oferece ou não perigo.

Realçando a importância da manifestação psiquiátrica, Elias Abdalla-Filho, Miguel Chalub e Lisieux E. de Borba Telles (2016, p. 203) esclarecem que é a Psiquiatria que fornece as informações acerca da existência ou não de enfermidade mental, perturbação da saúde mental ou transtorno em determinada pessoa, de maneira a definir se a pessoa demonstra aptidão mental

Revista Brasileira de Direito Civil em Perspectiva | e-ISSN: 2526-0243| Porto Alegre | v. 4 | n. 2 |

p. $20-38$ | Jul/Dez. 2018 


\section{ESTATUTO DA PESSOA COM DEFICIÊNCIA, DIREITOS FUNDAMENTAIS E OS CONFLITOS DIANTE DA REALIDADE EMPÍRICA: BREVES APONTAMENTOS SOB A ÓTICA DO DIREITO E DA PSIQUIATRIA}

suficiente que lhe permita gerir de forma autônoma seus interesses, de forma pragmática e objetiva, de acordo com seus valores e história de vida.

Para a Psiquiatria, a avaliação do discernimento vincula-se aos elementos relacionados ao estado mental da pessoa que melhor permita aferição da cognição e a integridade do teste de realidade do indivíduo, investigando-se a memória, a atenção, a consciência, a orientação e a inteligência, analisando-se no contexto do mundo circundante e a reflexão sobre os dados da realidade (ABDALLA-FILHO; CHALUB; TELLES, 2016, p. 213). Interessante também o registro, no sentido de que, para referida ciência, existem gradações que geram diferenciações no âmbito da capacidade civil, porquanto há pessoas que possuem discernimento para casar, decidir onde morar, ou para consentir ou recusar tratamento, mas não possuem para gerir um grande patrimônio, por exemplo, como também podem possuir discernimento para administrar um benefício de aposentadoria, mas não o de comandar uma grande empresa ou firmar um testamento ou efetuar uma doação.

Conforme se constata, o Direito, sozinho, não encontra resposta aos mais variados problemas da sociedade moderna. Para tanto, discute-se e defende-se inclusive uma nova hermenêutica, dialógica, construtiva, na linha de pensamento de Paulo Magalhães da Costa Coelho (2005, p. 7-19), volvida à interdisciplinariedade, sobremodo a Psiquiatria, neste estudo, definindo a questão alusiva ao consentimento válido ou consciente, à compreensão daquilo que pretende realizar, uma vez que é plenamente pertinente e exigência indelével de que, para que a pessoa possa praticar atos na vida civil, deva possuir suficiente entendimento de todas as implicações jurídicas, morais, familiares e sociais decorrentes.

Haverá situações em que o legal se distanciará do real, nas quais o direito é reconhecido por lei, mas a realidade concreta impedirá a sua efetivação, ou seja, em casos concretos, poderá haver a possibilidade de restrição à autonomia de pessoas com deficiências como decorrência inerente à própria limitação mental, por exemplo, o que não impõe, nesses casos, a observância do devido processo legal, realização de perícia médica e eventual deliberação com fins restritivos, mas de cunho protetivo, mesmo porque, obtempere-se, a pessoa humana deve ser vista na sua integralidade, e a mente humana não é compartimentada, ou seja, a proteção é a pessoa toda, e 
não apenas a uma parte dela, daí porque essas nuances são extraídas da imprescindível ciência médica.

Anote-se, v.g., uma pessoa com esquizofrenia. Segundo Nicholas Tarrier e Rumina Taylor "esquizofrenia é uma doença mental grave, caracterizada por sintomas positivos de alucinações, delírios e transtornos do pensamento" (BARLOW, 2016, p. 501), elementos que , na expressão dos autores, costumam ser bizarros, muitas vezes envolvendo uma interpretação equivocada da percepção ou da vivência, transtorno complexo que pode durar a vida toda, inclusive com episódios psicóticos (BARLOW, 2016, p. 506).

Nessa linha de raciocínio, veja-se o caso de pessoa com transtorno bipolar com classificação grave F31.13, que causa sofrimento sério e de difícil manejo, interferindo no funcionamento social e profissional de forma acentuada, exigindo supervisão praticamente continua a fim de prevenir dano físico a si ou a outros (NASCIMENTO, 2017, p. 154), posto que se trata de transtorno com vários graus e, dependendo do caso, gera vinculação a episódios maníaco-depressivos, com severa instabilidade do humor.

Adotando-se uma análise superficial acerca das exemplificações anteriores, são pessoas, à luz da Lei da Inclusão, capazes, mesmo que relativamente, e que possuem, por imperativo legal, direitos existenciais inerentes à sua própria essência humana. $\mathrm{Na}$ realidade concreta, possivelmente, eventual curatela, após investigação e parecer multidisciplinar, há séria possibilidade de a curatela limitada ao aspecto negocial e patrimonial afigurar-se insuficiente para a integral proteção e otimização dos valores inerentes à dignidade da pessoa com esquizofrenia.

\section{DIREITOS FUNDAMENTAIS DA PESSOA COM DEFICIÊNCIA E A REALIDADE EMPÍRICA: A PROBLEMÁTICA NO CONTEXTO SOCIAL E A NECESSIDADE DE RELEITURA DO INSTITUTO DA CURATELA}

A essencialidade dos direitos fundamentais vincula-se à liberdade e à dignidade humana, posto que constituem valores históricos e filosóficos que conduzem ao significado de 


\section{ESTATUTO DA PESSOA COM DEFICIÊNCIA, DIREITOS FUNDAMENTAIS E OS CONFLITOS DIANTE DA REALIDADE EMPÍRICA: BREVES APONTAMENTOS SOB A ÓTICA DO DIREITO E DA PSIQUIATRIA}

universalidade inerente a esses direitos como ideal da pessoa humana (BONAVIDES, 2018, p. 576).

Entretanto, o direito se dirige ao ser humano histórico, envolvido em uma dada realidade social e concreta, e não um ente envolvido em grau de abstração. Com efeito, é na reflexão acerca de casos reais, dos conflitos intersubjetivos e sociais, que se há de levar em conta os atores sociais concretos, a demanda por justiça, por igualdade, por dignidade humana, nas palavras de Paulo Magalhães da Costa Coelho (2005, p. 18), uma vez que o homem não é um sujeito abstrato.

O caráter altruístico do múnus da curatela impõe a adoção medidas que permitam a concretização do ideal de dignidade humana da pessoa com deficiência. Mesmo a despeito de discussões travadas em relação à aplicabilidade ou não do Código de Processo Civil no tocante à extensão da curatela a atos não patrimoniais, uma interpretação construtivo-argumentativa fincada em preceitos constitucionais, na boa-fé objetiva e na própria filosofia ética e protetiva da Lei da Inclusão, autorizaria uma possível solução para situações de reconhecida complexidade.

Pois bem. A legislação especial, a princípio, não permite estágios da curatela. Ao contrário, a Lei Federal n. ${ }^{\circ}$ 13.146/2015 é taxativa, limitando-a aos atos de administração de bens e negociais. Ocorre que, à luz da psiquiatria, conforme exposto no capítulo anterior, há pessoas com impedimentos nos mais variados graus. Algumas, com plena aptidão de gozo e exercício no mundo dos fatos no tocante a todos os direitos consagrados na legislação. Outras, por seu turno, sequer possuem, à vista da literatura psiquiátrica, qualquer possibilidade de exercício dos direitos garantidos por lei, dependendo do grau de transtorno. Imagine-se a questão envolvendo esterilização autorizada por uma pessoa do gênero feminino que revela indicativos, por exemplo, de ausência de expressão consciente de vontade, mas que, à vista do Estatuto possui capacidade para decidir sobre os seus direitos reprodutivos.

A complexidade das relações na sociedade atual e a própria densidade do ser humano em sua integralidade física, mental, psicológica e circunstancial trazem fatos que merecem ser apreciados, compreendidos e resolvidos, cabendo ao intérprete e aplicador da norma, diante das peculiaridades do caso, otimizar a regular argumentação jurídica, atentando-se para o art. 93, IX, da Constituição Federal, e o art. 489, parágrafo primeiro, do Código de Processo Civil, através de uma decisão técnica e com fundamentação adequada, observando-se e delineando-se os aspectos

Revista Brasileira de Direito Civil em Perspectiva | e-ISSN: 2526-0243| Porto Alegre | v. 4 | n. 2 |

p. 20 - 38 | Jul/Dez. 2018 
legais, os precedentes acerca do tema, com coerência ao sistema, o enquadramento na dogmática elaborada pela ciência do direito, como também as limitações das regras da ordem jurídica (LORENZETTI (2010, p. 159-163),

Uma das opções a serem refletidas seria o curador acionar a máquina judiciária, postulando uma tutela jurisdicional protetiva, a fim de que, respeitado o devido processo legal substancial e formal, seja emitido juízo decisório que eventualmente restrinja determinado direito fundamental, através de decisão argumentativamente desenvolvida, com o objetivo de proteção à pessoa em estado de vulnerabilidade, diante de um caso concreto específico e sob a ótica da proporcionalidade, critério racional para que garantir o respeito a eventual restrição a direito fundamental em cada caso, até porque, consoante destaca Ricardo Lobo Torres (2001, p. 266267) "A dignidade humana e as condições materiais da existência não podem retroceder aquém de um mínimo, do qual nem os prisioneiros, os doentes mentais e os indigentes podem ser privados"

Ora, a própria Lei n. 13.146/2015, ao alterar o art. 1.772 do Código Civil, estabeleceu que "O juiz determinará, segundo as potencialidades da pessoa, os limites da curatela, circunscritos às restrições constantes do art. 1.782, e indicará curador, levando em conta a vontade e as preferências do interditando, a ausência de conflito de interesses e de influência indevida, a proporcionalidade e a adequação às circunstâncias da pessoa".

No respeitante à dignidade humana e a proporcionalidade, o novo Código de Processo Civil também consagrou referidos preceitos, nos artigos $1 .^{\circ}$ e $8 .^{\circ}$. Nesse contexto, em relação à proporcionalidade, esclarece Gilmar Mendes (2018, p. 227 e 229) que se cuida de indispensável limite ou parâmetro a ser utilizado como meio protetivo dos limites atinentes à potencial restrição de direito fundamental, observado, destarte, à vista dos três subprincípios, quais sejam: adequação, necessidade e proporcionalidade em sentido estrito.

Enfatizando a problemática entre os direitos incorporados na novel legislação e os riscos de potencial dano à própria pessoa com deficiência, quando do cotejo com a situação concreta da vida, José Fernando Simão (2015) assevera que a situação imposta pelo Estatuto às pessoas que necessitam de proteção é dramática. E exemplifica, discorrendo sobre os problemas relacionados a prescrição e decadência, que não mais correrá; pessoas que por fatores físicos são incapazes de 


\section{ESTATUTO DA PESSOA COM DEFICIÊNCIA, DIREITOS FUNDAMENTAIS E OS CONFLITOS DIANTE DA REALIDADE EMPÍRICA: BREVES APONTAMENTOS SOB A ÓTICA DO DIREITO E DA PSIQUIATRIA}

manifestar sua vontade, mas passam a ser capazes por força da nova lei; alguém com deficiência leve, mas com déficit cognitivo, e considerado relativamente incapaz por sentença, assinar um contrato que lhe é desvantajoso.

De igual sorte, Vitor Kümpel (2015) apresenta crítica à conflituosidade gerada na realidade entre as alterações introduzidas no contexto das incapacidades, enfatizando a desarmonia intolerável para o sistema, aduzindo que "Com o advento e a entrada em vigor do Estatuto, o deficiente ou enfermo mental sem qualquer discernimento será, por regra geral, responsável, porém, inimputável. Por ficção, entenderá o ilícito civil e determinar-se-á de acordo com esse entendimento; porém, não entenderá esse mesmo ilícito, isto é, o fato gerador sob o aspecto penal. Como é possível entender e deixar de entender a mesma situação?”

Acerca da controvérsia gerada, Célia Barbosa Abreu, incorpora as razões críticas e arremata:

[...] o Estatuto erra no final da nova redação dada ao art. 1.772, CC/2002, ao estabelecer que os limites da curatela ficam 'circunscritos às restrições constantes do art. 1.782'. Teria sido mais acertado nesta parte usar os termos do CC/2002, ou seja, 'podendo ser os constantes do art. 1.782 ', de maneira que a medida da proteção poderia ser necessária até para evitar atos extraordinários patrimoniais capazes de trazer prejuízo para o patrimônio do interdito ou não (MENEZES, 2016, p. 560).

Apresentando possibilidades para adequação do jurídico para a realidade prática, Joyceane Bezerra de Menezes (2016, p. 525), professa que, como medida restritiva primeira, antes de ver ceifada a sua autonomia, poderia ser adotado o processo de tomada de decisão apoiada, medida de apoio mais branda (art. 84). Excepcionalmente, contudo, verificada a ausência do discernimento, por meio das cautelas devidas e, no âmbito do devido processo legal, defende ser possível restringir-lhe a autonomia e fixar-lhe a curatela.

Em estudo sobre o assunto, Iara Antunes de Souza (2016, p. 325) pontifica que as alterações realizadas pelo Estatuto da Pessoa com Deficiência não atingiram o novo Código de Processo Civil. A autora defende ser possível o reconhecimento da incapacidade civil da pessoa com deficiência mental ou intelectual e sua interdição junto a um processo democrático, com a avaliação realizada por equipe multidisciplinar, desde que a medida, que é excepcional, se

Revista Brasileira de Direito Civil em Perspectiva | e-ISSN: 2526-0243| Porto Alegre | v. 4 | n. 2 |

p. $20-38$ | Jul/Dez. 2018 
justifique como medida de cuidado, de promoção da pessoa com deficiência. Para tanto, imprescindível, na visão da autora, a fiel observância pelo magistrado do disposto nos artigos 489 e 753 do Código de Processo Civil, de maneira que o juiz fundamente a sua decisão, relacionando os meios de prova, em especial, o laudo da equipe multidisciplinar e suas impressões pessoais extraídas da audiência de entrevista, com a real necessidade da pessoa curatelanda, a fim de que, tendo em vista as peculiaridades da pessoa, seja preservada a sua autonomia na maior medida possível.

Algumas proposições são desenvolvidas por Thaís Fernanda Tenório Sêco ao sustentar, até mesmo, a cisão da tutela, atribuindo os poderes e deveres a pessoas diferentes, no caso, "pode a pessoa com deficiência assumir somente os aspectos compatíveis com sua condição, ficando outros aspectos atribuídos a outra pessoa, sempre com foco na promoção do interesse do tutelado" (MENEZES, 2016, p. 438), como também [...] "a pessoa com deficiência, ainda que sob curatela, poderá, conforme o caso concreto, estar plenamente apta a assumir a tutela em seus aspectos existenciais, ainda que não esteja apta a fazê-lo nos aspectos patrimoniais". No respeitante à curatela, por sua vez, a autora (MENEZES, 2016, p. 438) recomenda "um duplo juízo de pertinência: um com relação ao curatelado, para saber se é mesmo o caso de instituir-se a curatela"; outro com relação ao curador, para avaliar sua aptidão ao exercício da curatela tendo-se sempre em vista o interesse precípuo do curatelado.

Conforme vários exemplos relacionados, inúmeras as situações de conflito entre a normatividade e a realidade. Anote-se, repise-se, a questão do casamento, do divórcio, da constituição de união estável, entre tantos direitos existenciais. A legislação reconhece a capacidade plena, mas tais atos jurídicos necessitam, para perfectibilização, da demonstração da autonomia decorrente da autodeterminação e consciência em relação à seriedade do ato, sob pena de prejuízo aos interesses da própria pessoa cuja proteção se pretende.

Os tribunais brasileiros iniciaram a discussão envolvendo os dilemas ora em reflexão, evidenciando-se entendimentos, tanto pela inviabilidade da incapacidade civil absoluta, quanto pela mantença da sua ocorrência. Com efeito, independente do entendimento perfilhado, indiscutível que eventual juízo decisório em relação à extensão da curatela a questões extrapatrimoniais, de maneira excepcional, em se tratando de restrição de direitos, impõe a 


\section{ESTATUTO DA PESSOA COM DEFICIÊNCIA, DIREITOS FUNDAMENTAIS E OS CONFLITOS DIANTE DA REALIDADE EMPÍRICA: BREVES APONTAMENTOS SOB A ÓTICA DO DIREITO E DA PSIQUIATRIA}

observância de valores estabelecidos no ordenamento jurídico, notadamente aqueles com a natureza de princípio fundamental, exigindo, no dizer de Willis Santiago Guerra Filho (2017, p. 121), um procedimento decisório sob o pálio do devido processo legal, estruturado de uma forma tal que garanta a maior racionalidade e objetividade possíveis da decisão, para atender ao imperativo de realização de justiça.

Acredita-se que a solução para o caso impõe um equilíbrio. Pode-se sustentar a dignidade-liberdade como regra, garantindo-se e preservando-se os direitos existenciais plenos e necessários a uma vida digna, e, em casos excepcionais, quando realmente haja a demonstração de ausência de autodeterminação vinculada à autonomia do gênero humano, concretamente e à vista da própria proporcionalidade de cada caso concreto, aplicar-se a máxima da dignidadevulnerabilidade. Há, de fato, a necessidade de alterações legislativas, a fim de que se permita uma maior maleabilidade nos casos de curatela, quando diante de situações excepcionais, de maneira a se preservar a própria dignidade e respeito de pessoas com deficiência, com todas as garantias legais, acompanhamento da própria pessoa, familiares, defensoria pública e ministério público, até mesmo para correção de antinomias entre o Estatuto da Pessoa com Deficiência e o Código de Processo Civil, permitindo-se que o juiz, de acordo com as conclusões da equipe multidisciplinar, fixe, na sentença, os limites da curatela, especificando os atos que a pessoa curatelada dependerá de assistência ou representação, com base no grau de autodeterminação para os casos específicos.

Quiçá sejam condensados os ideais de Konrad Hesse (1991), no sentido de que:

A constituição não configura, portanto, apenas expressão de um ser, mas também de um dever ser; ela significa mais do que o simples reflexo das condições fáticas de sua vigência, particularmente as forças sociais e políticas. Graças à pretensão de eficácia, a Constituição procura imprimir ordem e conformação à realidade política e social [...].

Conjuntamente com os fatores reais de poder de Lassalle (2005, p. 35), de maneira que a constituição jurídica e a real do nosso país integram uma única força e projeto, na busca do consenso em relação à concretização de direitos e valores constitucionais em prol da vida digna das pessoas com deficiência.

Para tanto, imperiosa a vontade humana convergente, a participação da sociedade civil, dos integrantes do poder político estatal, das famílias, entidades não governamentais, posto que,

Revista Brasileira de Direito Civil em Perspectiva | e-ISSN: 2526-0243| Porto Alegre | v. 4 | n. 2 |

p. 20 - 38 | Jul/Dez. 2018 
sem o concurso da vontade humana, dialogicamente desenvolvida, a força ativa da Constituição não evoluirá e correrá o risco de se deslegitimar, para tanto, indispensável o resgate do sentimento da constituição, sustentado por Verdú (2006, p. 127-152), para quem a efetividade constitucional requer sentimento constitucional, que aflora em momentos críticos, e é o referido sentimento, essa adesão em relação aos valores constitucionais relacionados à dignidade da pessoa que dão sustentáculo à normatividade e à dogmática.

\section{CONCLUSÃO}

O presente artigo relaciona-se ao Estatuto da Pessoa com Deficiência, arcabouço legislativo que revolucionou o paradigma atinente à capacidade civil do ser humano, notadamente as pessoas com impedimento de longo prazo de natureza física, mental, intelectual ou sensorial.

Inicialmente fora realizada abordagem em relação às inovações trazidas pela Lei Brasileira da Inclusão, com alusão a dignidade humana e a autonomia do gênero humano, perpassando-se pela intertextualidade com a Psiquiatria e traçando-se contornos volvidos à problemática trazida à colação no respeitante ao contexto da realidade fática.

O estudo revelou a indispensabilidade dos direitos fundamentais da pessoa com deficiência como lineamentos fundantes da sua própria dignidade como ser humano, com direito a uma vida digna e respeitosa no tocante à autonomia do gênero humano, e, noutra vertente, buscou fomentar reflexões e questionamentos, quando da análise dos direitos, sobretudo extrapatrimoniais, na realidade fática.

Verificou-se que há posições divergentes sobre o assunto, mas se reconheceu a possibilidade de extensão da curatela no que pertine a atos extrapatrimoniais, quando, após manifestação multidisciplinar elaborado, constatar-se a redução na autodeterminação e autonomia da pessoa com deficiência, de maneira que a extensão da curatela, com fundamento na própria proteção à dignidade e nos artigos 753, parágrafo 2. e 755 do Código de Processo Civil, sirva de sustentáculo protetivo à pessoa com deficiência que, no plano real, não disponha de condições de exprimir conscientemente a sua vontade.

Revista Brasileira de Direito Civil em Perspectiva | e-ISSN: 2526-0243| Porto Alegre | v. 4 | n. 2 |

p. $20-38$ | Jul/Dez. 2018 


\section{ESTATUTO DA PESSOA COM DEFICIÊNCIA, DIREITOS FUNDAMENTAIS E OS CONFLITOS DIANTE DA REALIDADE EMPÍRICA: BREVES APONTAMENTOS SOB A ÓTICA DO DIREITO E DA PSIQUIATRIA}

Por fim, concluiu-se que a vedação da extensão da curatela pode prejudicar os interesses do curatelado e, bem assim, que a decisão eventualmente extensiva dos efeitos da curatela deverá respeitar o devido processo legal, com participação da Defensoria Pública, na defesa dos interesses da pessoa curatelada, bem como da própria curatelada, e do Ministério Público, demonstrando o caráter protetivo da medida excepcional, máximo no tocante ao aspecto extrapatrimonial, de maneira argumentativamente adequada, racional e proporcional, através dos subprincípios da adequação, necessidade e proporcionalidade em sentido estrito.

Evidente que se está em uma fase embrionária da análise dessa nova roupagem da curatela e das medidas protetivas em relação à pessoa com deficiência, com o foco na concretização dos direitos e valores consagrados na Constituição, na ordem internacional e na legislação especial. A dialogicidade afigura-se indispensável na seara do direito constitucional, civil e de família, incursionando sobre outras disciplinas jurídicas e ciências afins, envolvendo os atores políticos, jurídicos e sociais atuantes na sociedade pós-moderna e complexa, de maneira que se prime pelo respeito, mas que também não se adote um formalismo bizantino que venha a macular a beleza da dignidade e a efetivação de direitos fundamentais envoltos na almejada concretização constitucional, permitindo-se a densificação da vontade constitucional de construção uma sociedade livre, justa e solidária como objetivo fundamental da República Federativa Brasileira.

\section{REFERÊNCIAS}

ATLAS MUNDIAL DA SAÚDE. Disponível em: http://www.who.int/mental health/evidence/atlas/mental health atlas 2017/en/. Acesso em: 28. ago. 2018.

ABDALLA-FILHO, Elias; CHALUB, Miguel; TELLES, Lisieux E. de Borba. Psiquiatria forense de Taborda. 3. ed. Porto Alegre: Artmed, 2016.

ALEXY, Robert. Baez, Narciso Leandro Xavier. Da Silva, Rogério Luiz Nery. Dignidade humana, direitos sociais e não-positivismo inclusivo. 1. ed. Florianópolis: Qualis, 2015. 
BARCELlOS, Ana Paula de. A eficácia jurídica dos princípios constitucionais. O princípio da dignidade da pessoa humana. 3. ed. São Paulo: Renovar, 2011.

BARLOW, David H. Manual clínico dos transtornos psicológicos: tratamento passo a passo. Tradução. Roberto Cataldo Costa. 5. ed. Porto Alegre: Artmed, 2016.

BARROS, Daniel Martins; SERAFIM, Antônio de Pádua. Parâmetros legais para a internação involuntária no Brasil. Revista de Psiquiatria Clínica, v. 36, n. 4, p. 175-177, 2009.

BARROSO, Luís Roberto. A dignidade da pessoa humana no direito constitucional contemporâneo. A construção de um conceito jurídico à luz da jurisprudência mundial. Belo Horizonte: Fórum, 2016.

BONAVIDES, Paulo. Curso de direito constitucional. 33. ed. São Paulo: Malheiros, 2018.

BRASIL. Tribunal de Justiça do Rio de Janeiro. Apelação 0004362-34.2014.8.19.0007. Terceira Câmara Cível. Rel. des. Peterson Barroso Simão. Julgamento em 20 de setembro de 2017

BRASIL. Tribunal de Justiça de São Paulo. Apelação 1007607-79.2015.8.26.0565. Relator des. Fábio Podestá. $5^{\text {a }}$ Câmara de Direito Privado. Julgamento em 27 de junho de 2017

. Tribunal de Justiça de São Paulo. Apelação 1003765-94.2015.8.26.0564; Relator des. Alexandre Lazzarini. 9a Câmara de Direito Privado. Julgamento em 14 de março de 2017

COELHO, Paulo Magalhães da Costa. É possível a construção de uma hermenêutica constitucional emancipadora na pós-modernidade? Revista de Direito Constitucional e Internacional: RDCI, v. 13, n. 53, p. 7-19, out./dez. 2005.

DWORDIN, Ronald. Levando os direitos a sério. Tradução: Nelson Boeira. 3. ed. São Paulo: WMF Martins Fontes, 2010, Tiragem 2014. 


\section{ESTATUTO DA PESSOA COM DEFICIÊNCIA, DIREITOS FUNDAMENTAIS E OS CONFLITOS DIANTE DA REALIDADE EMPÍRICA: BREVES APONTAMENTOS SOB A ÓTICA DO DIREITO E DA PSIQUIATRIA}

GUERRA FILHO, Willis Santiago. Processo constitucional e direitos fundamentais. 7. ed. São Paulo: SRS, 2017.

HESSE, Konrad. A força normativa da Constituição. Tradução de Gilmar Ferreira Mendes. Porto Alegre: Sérgio Antônio Fabris, 1991.

KÜMPEL, Vítor. O estranho caso do inimputável capaz. Parte I. Disponível em: https://flaviotartuce.jusbrasil.com.br/artigos/245025824/o-estranho-caso-do-inimputavel-capazparte-i-por-vitor-kumpel. Acesso em: 26 ago. 2018.

LASSALLE, Ferdinand. O que é uma Constituição. 2. ed. Campinas: Minelli, 2005.

LORENZETTI, Ricardo. Teoria da decisão judicial: fundamentos de direito. 2. ed. São Paulo: Revista dos Tribunais, 2010.

MENDES, Gilmar Ferreira; BRANCO, Paulo Gustavo Gonet. Curso de direito constitucional. 13. ed. São Paulo: Saraiva, 2018.

MENEZES, Joyceane Bezerra de. Direito das pessoas com deficiência psíquica e intelectual nas relações privadas. Convenção sobre os direitos da pessoa com deficiência e Lei Brasileira de Inclusão. Rio de Janeiro: editora processo, 2016.

NASCIMENTO, Maria Inês Corrêa et al. Manual diagnóstico e estatístico de transtornos mentais. DSM-5. American Psychiatric Association. 5. ed. Porto Alegre: Artmed, 2014. Reimpressão 2017.

NOVAES, Jorge Reis. A dignidade da pessoa humana. Coimbra: Almedina, 2017. v. II.

RICHARDSON, Roberto Jarry et al. Pesquisa social: métodos e técnicas. 3. ed. São Paulo: Atlas, 1999.

SARLET, Ingo Wolfgang. Dignidade da pessoa humana e direitos fundamentais na Constituição Federal de 1988. 10. ed. Porto Alegre: Livraria do advogado, 2015.

Revista Brasileira de Direito Civil em Perspectiva | e-ISSN: 2526-0243| Porto Alegre | v. 4 | n. 2 |

p. 20 - 38 | Jul/Dez. 2018 
SARMENTO, Daniel. Dignidade da pessoa humana. Conteúdo, trajetórias e metodologia. 2. ed. Belo Horizonte: Fórum, 2016.

SIMÃO, José Fernando. Estatuto da Pessoa com Deficiência causa perplexidade. Parte I. Disponível em: https://www.conjur.com.br/2015-ago-06/jose-simao-estatuto-pessoa-deficienciacausa-perplexidade. Acesso em: 26 ago. 2018.

SOUZA, Iara Antunes de. Estatuto da pessoa com deficiência: curatela e saúde mental Conforme a Lei 13.146/2015. Belo Horizonte: D'Plácido, 2016.

TARTUCE, Flávio. Manual de Direito Civil. 8. ed. São Paulo: Método, 2018. Volume único.

TORRES, Ricardo Lobo. Teoria dos direitos fundamentais. 2. ed. Rio de Janeiro: Renovar, 2001.

VERDÚ, Pablo Lucas. Teoria do Estado, Teoria da Constituição e Sentimento Constitucional. In: O sentimento constitucional: Aproximação ao estudo do sentir constitucional como modo de integração política. Tradução e prefácio: Agassiz Almeida Filho. Rio de Janeiro: Forense, 2006. 